\title{
MICRO E PEQUENOS EMPREENDEDORES E O SEBRAE: PERCEPÇÃO DOS EMPRESÁRIOS E CONSULTORES ACERCA DO SERVIÇO PRESTADO E ESPECIFICIDADES DOS NEGÓCIOS
}

\author{
MICRO AND SMALL ENTREPRENEURS AND SEBRAE: PERCEPTION OF \\ ENTREPRENEURS AND CONSULTANTS ABOUT THE SERVICE PROVIDED \\ AND SPECIFICITIES OF THE BUSINESS
}

Recebido: 15/09/2017 - Aprovado: 14/03/2018 - Publicado: 26/06/2018 Processo de Avaliação: Double Blind Review

\author{
Irlla Oliveira ${ }^{1}$ \\ Graduada em Ciências Contábeis \\ Faculdade Santa Helena - FSH \\ irlla.santos@hotmail.com \\ Karla Tavares \\ Graduada em Ciências Contábeis \\ Faculdade Santa Helena - FSH \\ karlinha.r.tavares@gmail.com \\ Rômulo Santana \\ Graduado em Ciências Contábeis \\ Faculdade Santa Helena - FSH \\ romulo.santana36@hotmail.com \\ Juliana Gonçalves de Araújo \\ Doutoranda em Administração. \\ Universidade Federal de Pernambuco - UFPE \\ juhliana.araujo@gmail.com
}

RESUMO: O presente estudo buscou identificar as percepções dos empreendedores e consultores em relação à prestação de serviço do SEBRAE acerca das características, dificuldades e especificidades da gestão dos micro e pequenos empreendedores que utilizam os serviços de consultoria. O método de análise de dados foi a pesquisa

\footnotetext{
${ }^{1}$ Autor para correspondência: Faculdade Santa Helena - FSH - Av. Caxangá, 990 - Zumbi, Recife - PE, Brasil, 50711-095
}

REMIPE- Revista de Micro e Pequenas Empresas e Empreendedorismo da Fatec Osasco 
quantitativa, com preenchimento de questionário objetivo para os empresários, que foi coletado no local de atendimento disponibilizado pelo SEBRAE e, para os consultores, análise qualitativa por meio de roteiro de entrevista, que foram gravadas e descritas para facilitar a realização da análise. Dessa forma, foram extraídos dados que caracterizaram os empresários como gênero, idade e escolaridade, para os consultores tempo de atuação no atendimento e tipo de vínculo com o SEBRAE. As especificidades dos empresários foram ramo da empresa, tempo no mercado e conhecimento sobre contabilidade, os consultores perfil da empresa, ferramentas utilizadas e ações desenvolvidas. As dificuldades na visão do empresário estão relacionadas à estratégia de venda e propaganda e a crise econômica, na visão dos consultores representa a falta de planejamento de um plano de negócio. As informações alcançadas levaram à identificação de que a percepção que ambos os usuários possuem da consultoria ofertada pelo SEBRAE é favorável para que as empresas se mantenham no mercado, para tanto devem ser seguidas corretamente as orientações não apenas as tributárias, mas também as gerenciais.

Palavras-Chave: Microempresas; SEBRAE; Contabilidade gerencial; Empreendedorismo.

ABSTRACT: This study aims to identify the perceptions of entrepreneurs and consultants in relation to SEBRAE's service delivery about the characteristics, difficulties and specificities of the management of micro and small entrepreneurs who use consulting services. The method of data collection occurred through quantitative surveys with the completion of an objective questionnaire for the entrepreneurs, where they were collected at the place of attendance provided by SEBRAE and for the consultants qualitative analysis through an interview script, which were recorded and described for facilitate the analysis. In this way, data were extracted that characterized the entrepreneurs as gender, age and educational level, for the consultants time to act in the service and type of bond with SEBRAE. The specifics of the entrepreneurs were branch of the company, time in the market and knowledge about accounting, the company profile consultants, tools used and actions developed. The difficulties in the entrepreneur's vision are related to the strategy of selling and advertising and the economic crisis, in the view of the

REMIPE- Revista de Micro e Pequenas Empresas e Empreendedorismo da Fatec Osasco

V. 4, No1, jan.-jun. 2018. 
consultants represents the lack of planning of a business plan. The information obtained led to the identification that the perception that both users have of the consultancy offered by SEBRAE, is favorable for companies to remain in the market, so the guidelines should be followed correctly, not only the tax, but also the management.

Keywords: Microenterprises; SEBRAE; Management Accounting; Entrepreneurship.

\section{INTRODUÇÃO:}

O conteúdo em questão abrange a área da contabilidade responsável por fornecer informações relevantes a uma empresa, chamada contabilidade gerencial. Ela é utilizada para favorecer benefícios, como melhorar a saúde financeira da empresa, reduzir os custos, aumentar a lucratividade ou desenvolver um planejamento estratégico (BRIZOLLA, 2008).

A contabilidade existe de forma empírica há muitos anos, porém obteve maior importância após o surgimento das grandes empresas de indústria e comércio, assim havendo a necessidade de disseminá-la em diversas áreas nas quais a contabilidade gerencial é responsável pela influência na tomada de decisão, através de relatórios financeiros e projeções devidamente acompanhadas e controladas (BRIZOLLA, 2008). Para tanto, ela conta com uma subdivisão de atividades, como controle de gastos gerais, contas a pagar e contas a receber informar desembolsos e ganhos futuros em caixa; sistema orçamentário, que compreende a previsão, o controle e avaliação das informações passadas e futuras, fluxo de caixa prevê os ingressos e desembolsos de curto prazo, análise financeira avalia ou estuda a viabilidade, estabilidade e capacidade de lucro de um negócio ou projeto (BRIZOLLA 2008, p. 14 e 15).

Apesar da relevância destes relatórios, sua elaboração é de utilização empresarial interna, sendo assim os relatórios financeiros apresentados pela contabilidade gerencial não são aceitos pelos órgãos governamentais como o Fisco e a Comissão de Valores Mobiliários (CVM). Portanto, seu objetivo fundamental está voltado à administração da empresa para suprir informações de maneira relevante e tempestiva para a tomada de decisão (IUDíCIBUS 1998, p. 21).

REMIPE- Revista de Micro e Pequenas Empresas e Empreendedorismo da Fatec Osasco 
Partindo desse conceito, observa-se a necessidade da utilização da contabilidade gerencial para pequenas empresas brasileiras. Segundo o site do SEBRAE (Serviço Brasileiro de Apoio às Micro e Pequenas Empresas), os dados atuais indicam que cerca de 9 milhões de micro e pequenas empresas geram 27\% do PIB (Produto Interno Bruto) do Brasil. De acordo com a estimativa realizada durante o período de dez anos, esse índice caracteriza um montante de $\mathrm{R} \$ 144.000 .000 .000,00$ (cento e quarenta e quatro bilhões de reais) para $\mathrm{R} \$ 599.000 .000 .000,00$ (quinhentos e noventa e nove bilhões). Apesar desse resultado, a realidade revela que $31 \%$ das empresas estão decretando falência, dentre as quais $88 \%$ são pequenas empresas. Que, por sua vez, normalmente não possuem o serviço contábil interno e recorrem a prestadores de serviço, como escritórios ou autônomos.

Mediante esse cenário, o objetivo deste estudo é verificar a percepção dos empreendedores e consultores do SEBRAE acerca das características, dificuldades e especificidades da gestão dos micro e pequenos empreendedores que utilizam os serviços do SEBRAE. Para tanto, realizaram-se entrevistas envolvendo consultores, contadores e empresários que buscam esse atendimento, além de aplicação de questionários aos empresários.

Este estudo é relevante para quem busca informação a respeito de como os empresários que visitam o SEBRAE atuam e como eles veem tal prestação de serviço, além de favorecer o entendimento a respeito de como os consultores atuam no âmbito do que eles ofertam. A região abordada possui um grande número de empresas de micro e pequeno porte, que contribuem com a economia e geram empregos. O SEBRAE apresenta-se como fonte de apoio e mesmo assim existe o índice de falência. O intuito é relacionar esses fatos e mostrar as possíveis dificuldades dos empreendedores na gestão dessas empresas considerando suas particularidades.

\section{REVISÃO DA LITERATURA;}

A estrutura da Revisão da Literatura contempla o tópico de Contabilidade Gerencial, haja vista o objetivo de compreender a sua utilização pelos microempreendedores, além de possuir papel relevante na gestão e tomada de decisão de organizações de qualquer porte. Esta Revisão de Literatura também abrange Pequenas 
Empresas e Mortalidade, O SEBRAE e Sua Atuação em Micro e Pequenas Empresas e Estudos Sobre Micro e Pequenas Empresas.

\subsection{CONTABILIDADE GERENCIAL;}

A atuação do processo contábil é iniciada pela coleta de dados econômicos, que são mensurados, registrados e sumarizados para, na sequência, serem apresentados como relatórios que auxiliarão os usuários na tomada de decisão. $\mathrm{O}$ administrador, por sua vez, é um usuário da contabilidade e as informações contidas auxiliarão em uma administração eficiente na empresa (MARION, 2011, P.17).

A contabilidade gerencial existe como uma ferramenta administrativa que pode ser utilizada pelo contador ou pelo responsável administrador da empresa, de forma que atenda a todas as pessoas da empresa independente do nível de hierarquia. Sendo assim, ela tem uma estrutura detalhada, não possui modelo específico de relatório e nem está ligada aos princípios contábeis, o que possibilita liberdade no uso de critérios (GARRISON, 2013).

Para Raza (2008, p. 16), “a falta de informações é o grande vilão nas pequenas empresas". A maioria dos empreendedores que possuem o capital financeiro e montam um negócio desconhece todos os outros fatores necessários ao sucesso do empreendimento tais como: o conhecimento da movimentação do capital de giro, o entendimento de receita e despesas, um controle dos custos para uma continuidade do negócio, estudo do mercado de trabalho, entre outros.

Para que uma empresa alcance bons resultados, é importante que aconteça a relação entre a contabilidade gerencial e a administração, pois uma será o auxílio para a eficiência da outra. A partir dessa junção verifica-se a necessidade das técnicas que compõe a contabilidade gerencial, uma vez que é possível avaliar a situação real da entidade nos âmbitos econômico, financeiro e patrimonial. Tal aspecto é relevante porque parte das empresas de pequeno porte tende a decretar falência em um prazo curto.

Os empresários de pequenas empresas, na sua grande maioria, acabam não dando o devido valor à contabilidade gerencial como um instrumento de apoio para boas tomadas de decisão. Isso ocorre devido ao aumento das solicitações burocráticas que são as exigências do fisco que as empresas devem cumprir para continuar regulares. Segundo 
Chér (1991, p. 36), "a contabilidade tem sido encarada como um instrumento tão somente para se atender a uma série de exigências legais e burocráticas, e não encarada como um instrumento de apoio à administração". Para Longenecker (1998, p. 515), é indispensável, para o administrador de uma pequena empresa que atua com informações financeiras, possuir o conhecimento em sistemas contábeis.

\subsection{SEBRAE;}

O SEBRAE é uma empresa privada, sem fins lucrativos, que ter por objetivo apoiar empresas de micro e pequeno porte de todo o país, promovendo a capacitação e o desenvolvimento dos empreendimentos com competitividade e sustentabilidade. Logo, gera estímulo para que o empresário possa agregar ao seu negócio inovação, tecnologia, educação empreendedora, ambiente de trabalho saudável dentre outros métodos. Para tanto, o SEBRAE conta com uma equipe de consultores que analisam toda a estrutura do negócio e, por meio de orientações, permite que o pequeno empresário tenha condições de administrar o seu empreendimento e até mesmo expandir a sua marca. Esses consultores são preparados para atender os setores de comércio e serviço, indústria e agronegócio.

Anualmente, são publicados estudos sobre as expectativas para o ano seguinte em relação ao mercado de atuação, situação financeira do país, perfil dos empreendedores que procuram a empresa com o intuito de agregar o conhecimento através de capacitações como: palestras e a interação com os seus consultores que são disponibilizados para consultas pessoalmente nos endereços de cada região ou pelo site, de forma virtual e prática. Dessa maneira, propicia-se aos microempresários o conhecimento para boas tomadas de decisões.

Em Pernambuco, mais especificamente em Recife, foram constituídas 4.561 empresas e a taxa de sobrevivência atingiu 55\%. Com isso, observa-se que a tendência para o aumento da sobrevivência está ligada aos avanços verificados tanto no âmbito dos negócios, da parte burocrática, como na evolução das características dos empreendedores brasileiros. Nesse contexto, atesta-se que o SEBRAE está contribuindo de forma significativa para o entendimento dos empresários que possuem empresas desse porte. 


\subsection{ATUAÇÃO DO SEBRAE EM MICRO E PEQUENAS EMPRESAS;}

Segundo Chiavenato (2007), existe um grande fluxo de entrada de novas empresas de pequeno porte. Isso ocorre devido à condição favorável da nossa economia, porém na mesma proporção muitas delas decretam falência em pouco tempo. O motivo mais relevante para essas constatações é a falta de planejamento e administração do negócio.

De acordo com pesquisa realizada pelo SEBRAE em 2013, analisando empresas de 2007 abrangendo dados como a taxa de sobrevivência e mortalidade das pequenas empresas com enfoque na região do Nordeste, foi atestado que a taxa de sobrevivência de empresas com período de dois anos, classificadas por atividade, foi: Indústria 74,1\%, Comércio 75,5\%, Construção $63,5 \%$ e Serviço $62,9 \%$.

No intuito de reverter esse cenário, o SEBRAE contribui ao dar suporte a essas empresas. $\mathrm{O}$ atendimento é realizado de forma individual ou coletiva, atrelado às diversas maneiras de solução necessária para cada empresário que podem ser: Informações por meio de pesquisas, publicações e outros meios de informação. Orientações no processo de planejamento, abertura e formalização dos negócios. Projetos voltados a fortalecer um determinado setor abrangendo diversos segmentos. Consultoria cuja análise é realizada nos postos de atendimento do SEBRAE ou diretamente na empresa. Cursos e palestras que podem ser realizados presencialmente ou à distância, com um conteúdo válido para iniciação ou expansão de um negócio. No site é possível encontrar uma série de vídeos, textos e oficinas que são diferenciados conforme a área de gestão ou o segmento empresarial. E, por fim, a Premiação que tem o objetivo de destacar e agregar valor ao negócio, atendendo regras e critérios a serem seguidos se submetendo a etapas para alcançar as vantagens oferecidas para o ganhador. Em destaque o MPE Brasil que teve como objetivo estimular o aumento da qualidade, competitividade e produtividade das micro e pequenas empresas nacionais.

\subsection{ESTUDOS SOBRE MICRO E PEQUENAS EMPRESAS;}

Este tópico foi desenvolvido a fim de apresentar estudos que foram realizados envolvendo micro e pequenas empresas. Com temas vinculados à gestão e técnicas de melhoria para tais empresas, aborda-se assuntos como controladoria empresarial, controladoria como custo-benefício e gestão do conhecimento. Entende-se que as REMIPE- Revista de Micro e Pequenas Empresas e Empreendedorismo da Fatec Osasco 
informações contidas nos artigos pesquisados reforçam as limitações existentes nas micro e pequenas empresas em relação a planejamento, controle, visão estratégica e, principalmente, ao modo como elas atuam. Um resumo dos estudos pode ser visto no quadro 1.

Quadro 1: Resumo de Estudos Anteriores Mencionados na Seção:

\begin{tabular}{|c|c|}
\hline \multicolumn{2}{|r|}{ ESTUDO 1} \\
\hline Título & $\begin{array}{c}\text { CONTROLADORIA EMPRESARIAL: GESTÃO } \\
\text { ECONÔMICA PARA AS MICRO E PEQUENAS } \\
\text { EMPRESAS }\end{array}$ \\
\hline Fonte & Monteiro e Barbosa (2011) \\
\hline Descrição & $\begin{array}{l}\text { Com o objetivo de identificar a aplicação da controladoria } \\
\text { empresarial em micro e pequenas empresas, o estudo foi } \\
\text { realizado em Aracajú e envolveu } 40 \text { empresas. Logo, foram } \\
\text { levantadas informações a respeito do uso das ferramentas da } \\
\text { controladoria, visão do empresário e conhecimento. }\end{array}$ \\
\hline \multicolumn{2}{|r|}{ ESTUDO 2} \\
\hline Título & $\begin{array}{c}\text { A CONTROLADORIA COMO FERRAMENTA DE } \\
\text { GESTÃO NAS MICRO E PEQUENAS EMPRESAS: UM } \\
\text { ESTUDO DA VIABILIDADE E DA RELAÇÃO CUSTO } \\
\text { BENEFÍCIO }\end{array}$ \\
\hline Fonte & Fernandes e Galvão (2016) \\
\hline Descrição & $\begin{array}{l}\text { Os autores pesquisaram a controladoria como ferramenta de } \\
\text { gestão de micro e pequenas empresas. Por meio de pesquisa } \\
\text { bibliográfica, apresentam definições estratégicas, } \\
\text { características e conceitos das funços de controladoria. }\end{array}$ \\
\hline \multicolumn{2}{|r|}{ ESTUDO 3} \\
\hline Título & $\begin{array}{l}\text { PRÁTICAS DE GESTÃO DO CONHECIMENTO EM } \\
\text { MICRO E PEQUENAS EMPRESAS DE SERGIPE }\end{array}$ \\
\hline Fonte & Menezes e Olave (2015) \\
\hline Descrição & $\begin{array}{l}\text { Identificação das práticas de Gestão do conhecimento adotadas } \\
\text { por micro e pequenas empresas. Realizada em Sergipe, de } \\
\text { forma exploratória e descrita em abordagem qualitativa, realiza } \\
\text { estudo de caso de cinco empreendimentos no polo de } \\
\text { confecção com a utilização de roteiro de entrevistas que foram } \\
\text { aplicadas para clientes, representantes, fornecedores e } \\
\text { concorrentes. }\end{array}$ \\
\hline
\end{tabular}

Fonte: Elaborado pelos autores.

O primeiro estudo, intitulado "Controladoria empresarial: gestão econômica para as micro e pequenas empresas", tem como tema a Controladoria empresarial voltada para gestão econômica e foi elaborado por Monteiro e Barbosa (2011). Como objetivo de identificar a aplicação da controladoria empresarial em micro e pequenas empresas, o REMIPE- Revista de Micro e Pequenas Empresas e Empreendedorismo da Fatec Osasco 
estudo foi realizado em Aracajú e envolveu 40 empresas. Dessa forma, buscou-se informações a respeito do uso das ferramentas da controladoria, visão do empresário e conhecimento. Assim, atesta-se que o empresário tem a necessidade de tomar decisões estratégicas, além de ressaltar que as pequenas empresas detêm boa parte da economia do país e geram oportunidade de emprego. E, quando possuem controladoria empresarial, podem auxiliar na obtenção de melhores resultados. Há enfoque na aplicação de conceitos de gestão, planejamento, finanças e controle.

$\mathrm{Na}$ aplicação das entrevistas, dentre alguns assuntos abordados, destaca-se que a controladoria no âmbito das micro e pequenas empresas conta com algumas fontes, por exemplo, o SEBRAE. Este que fornece apoio no sentido de planejamento estratégico, por meio das consultorias e, nesse rol, o SEBRAE detém $62 \%$. Porém $60 \%$ das empresas não recebem orientações sobre planejamento estratégico. Isso ocorre porque, na maioria dos casos, o empregado se torna empresário e alcançar o nível tático.

O segundo estudo, desenvolvido por Fernandes e Galvão (2016), aborda a controladoria, envolvendo o custo-benefício, sendo assim pesquisaram a controladoria como ferramenta de gestão de micro e pequenas empresas. Realizada por meio de pesquisa bibliográfica, apresenta definições estratégicas, características e conceitos das funções de controladoria. Demonstra que a falta de conhecimento técnico leva à contratação de profissionais internos ou consultorias externas. A análise da situação financeira, econômica e patrimonial possibilita maior controle e visão estratégica. Dessa forma, mostra, por meio da relação custo-benefício, que a controladora pode se adaptar à estrutura organizacional de custo de qualquer empresa.

Na pesquisa envolvendo livros e sites, existe a presença do SEBRAE, como fonte de apoio às micro e pequenas empresas. No entanto, existe resistência para utilização da controladoria. De acordo com o estudo, as atividades demandadas pelas ferramentas de controle acompanham o porte da empresa, portanto o custo de implantação e manutenção da controladoria pode se adequar à estrutura financeira de cada empresa. Em contrapartida, existem os benefícios que consistem em reduzir custos, melhorar a rentabilidade, correta avaliação do patrimônio, redução de riscos, formação de preços, planejamento tributários, entre outros. Nesse sentido, a busca pela controladoria para o empresário representa um investimento.

REMIPE- Revista de Micro e Pequenas Empresas e Empreendedorismo da Fatec Osasco 
O terceiro estudo, elaborado por Menezes e Olave (2015), apresenta pesquisa referente a práticas de gestão do conhecimento em micro e pequenas empresas, com enfoque na identificação das práticas de Gestão do conhecimento adotadas por micro e pequenas empresas.

Realizada em Sergipe, esta pesquisa exploratória, de abordagem qualitativa realizou estudo de caso sobre cinco empreendimentos no polo de confecção e apresenta entrevistas que foram aplicadas a clientes, representantes, fornecedores e concorrentes. Os autores verificaram que reuniões, cursos, treinamentos e monitoramento são as principais práticas de gestão do conhecimento utilizadas por micro e pequenas empresas e que tais práticas favorecem uma gestão duradoura e a geração de valor.

\section{METODOLOGIA:}

A metodologia desta pesquisa foi constituída por meio da coleta de dados de entrevistas e questionários com o objetivo de verificar a percepção dos empreendedores e consultores do SEBRAE acerca das características, dificuldades e especificidades da gestão dos micro e pequenos empreendedores que utilizam os serviços do SEBRAE.

Para tanto, os autores elaboraram questões mediante instruções da orientadora. Foram elaboradas perguntas subjetivas para ambos os grupos e, em seguida, buscou-se contato com o SEBRAE, o que aconteceu via a troca de mensagens por telefone e e-mail com a gerente do setor de atendimento, que esteve sempre à disposição para contribuir com a pesquisa. Ela forneceu o contato do consultor analista, com o quem foi agendada uma reunião para apresentação do conteúdo da pesquisa, objetivo e questionários que seriam aplicados. De acordo com a experiência do analista do SEBRAE, foi sugerido que para os empresários fossem utilizados questionários fechados ao invés de entrevistas, para melhor atender ao perfil dos entrevistados e, para os consultores, um roteiro de entrevista.

Desse modo, foram reformulados os questionários e os roteiros de entrevista para aplicação nos dois grupos e novamente enviados para o consultor e analista, que autorizou a aplicação das entrevistas dentro da unidade SEBRAE - Ilha do Retiro. O primeiro questionário foi direcionado a empresários que buscam atendimento no SEBRAE. Eles o preencheram no local de atendimento. Foram necessários dois dias para atingir a quantidade almejada. O segundo questionário, referente aos consultores vinculados ao 
SEBRAE, que foram respondidos por empregados e voluntários. Para estes, as entrevistas também ocorreram no local de atendimento, sendo que foram gravadas seguindo o roteiro. Portanto, a amostra final da pesquisa foi de 36 empresários e 4 consultores.

Para sintetizar os dados coletados, utilizou-se como procedimento de análise e verificação, foram destacados os maiores índices. No caso dos consultores, as respostas foram apresentadas sob a forma de resumo. Em alguns casos mais relevantes, foram apresentadas citações com base nas palavras mencionadas pelos entrevistados.

\section{ANÁLISE DOS DADOS;}

Esta seção compõe-se de dois tópicos, em que cada um deles refere-se a um de entrevistados. O primeiro grupo relaciona-se aos empresários e o segundo aos consultores. Sendo assim, foi aplicada análise descritiva às respostas dos empresários, dos quais foram obtidos trinta e seis questionários, e análise qualitativa em relação aos consultores, contemplou quatro entrevistados.

\subsection{ANÁLISE DE QUESTIONÁRIOS - EMPRESÁRIOS;}

Esta análise de dados teve como objetivo de identificar as principais percepções dos empresários acerca dos serviços prestados pelo SEBRAE e suas especificações da contabilidade. Caracteriza-se como uma pesquisa de natureza quantitativa, uma vez que as técnicas implementadas para a coleta, foi a aplicação de questionários, que foram analisados previamente por um Consultor Analista do SEBRAE. Todos os questionários possuíam processos de codificação e análise dos dados e continham alternativas.

Observa-se no gráfico 1 , que os empresários entrevistados eram $56 \%$ de respondentes do gênero masculino.

Gráfico 1: Levantamento por gênero: 


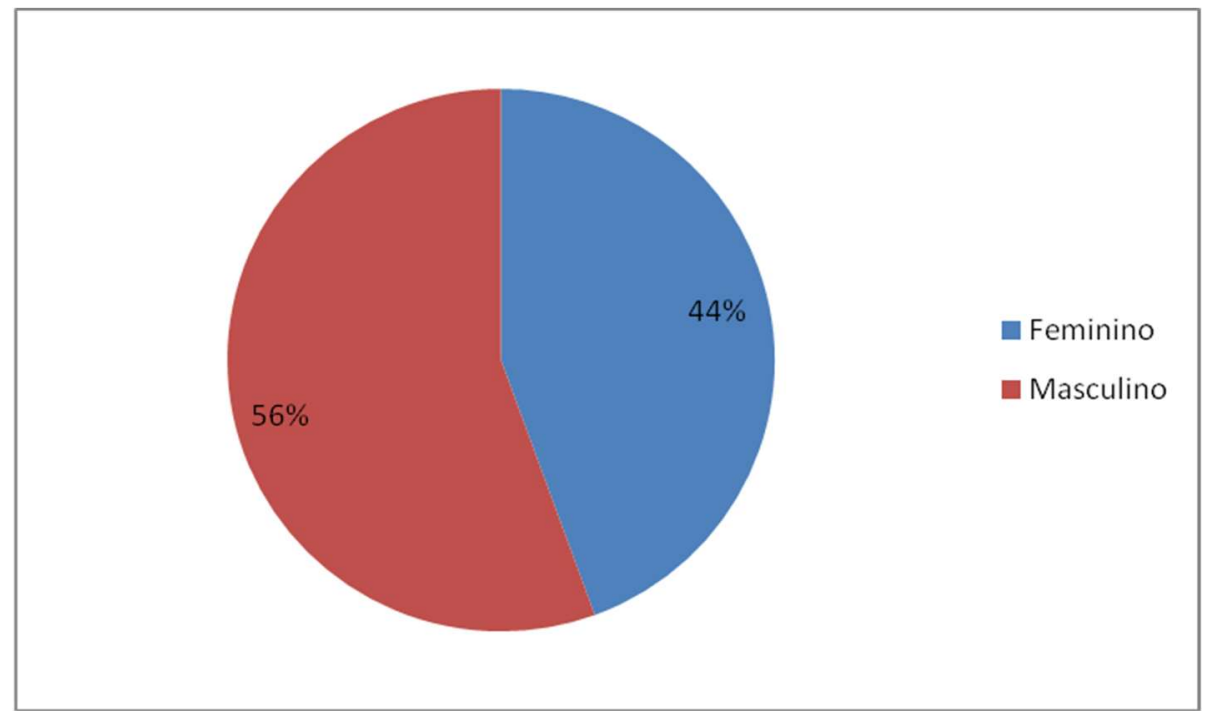

Fonte: Dados da pesquisa.

Observa-se na tabela 1, o intuito de realizar um levantamento da faixa etária dos empreendedores que procuram os serviços de consultoria do SEBRAE.

Tabela 1 - Levantamento por faixa etária:

\begin{tabular}{|c|c|c|}
\hline Descrição & $\begin{array}{c}\text { Quantidade de } \\
\text { empresários }\end{array}$ & Percentual \\
\hline 18-25 anos & 2 & $5,6 \%$ \\
$26-30$ anos & 8 & $22,2 \%$ \\
$31-35$ anos & 6 & $16,7 \%$ \\
$36-40$ anos & 5 & $13,9 \%$ \\
$41-45$ anos & 3 & $8,3 \%$ \\
$46-50$ anos & 4 & $11,1 \%$ \\
$51-55$ anos & 5 & $13,9 \%$ \\
56-60 anos & 2 & $5,6 \%$ \\
Acima de 60 anos & 1 & $2,8 \%$ \\
Total & 36 & $100 \%$ \\
\hline
\end{tabular}

Fonte: Dados da pesquisa.

A tabela 2 apresenta a terceira pergunta realizada para os empresários e observase que os donos de negócios que possuem até o ensino médio ocupam um percentual de $38,9 \%$ dos entrevistados, os empresários com graduação completa ocupam percentual de $33,3 \%$.

Tabela 2 - Levantamento por escolaridade:

REMIPE- Revista de Micro e Pequenas Empresas e Empreendedorismo da Fatec Osasco 


\begin{tabular}{|c|c|c|}
\hline Descrição & Quantidade de empresários & Percentual \\
\hline Até o ensino fundamental & 4 & $11,1 \%$ \\
Até ensino médio & 14 & $38,9 \%$ \\
Cursando Ensino Superior & 5 & $13,9 \%$ \\
Graduação Completa & 12 & $33,3 \%$ \\
Pós graduação & 1 & $2,8 \%$ \\
Total & 36 & $100 \%$ \\
\hline
\end{tabular}

Fonte: Dados da pesquisa.

O gráfico 2 apresenta que $69 \%$ que responderam estar voltado para o ramo da prestação de serviço, o que se referente a 25 dos 36 empresários entrevistados.

Gráfico 2 - Levantamento sobre o ramo das Microempresas:

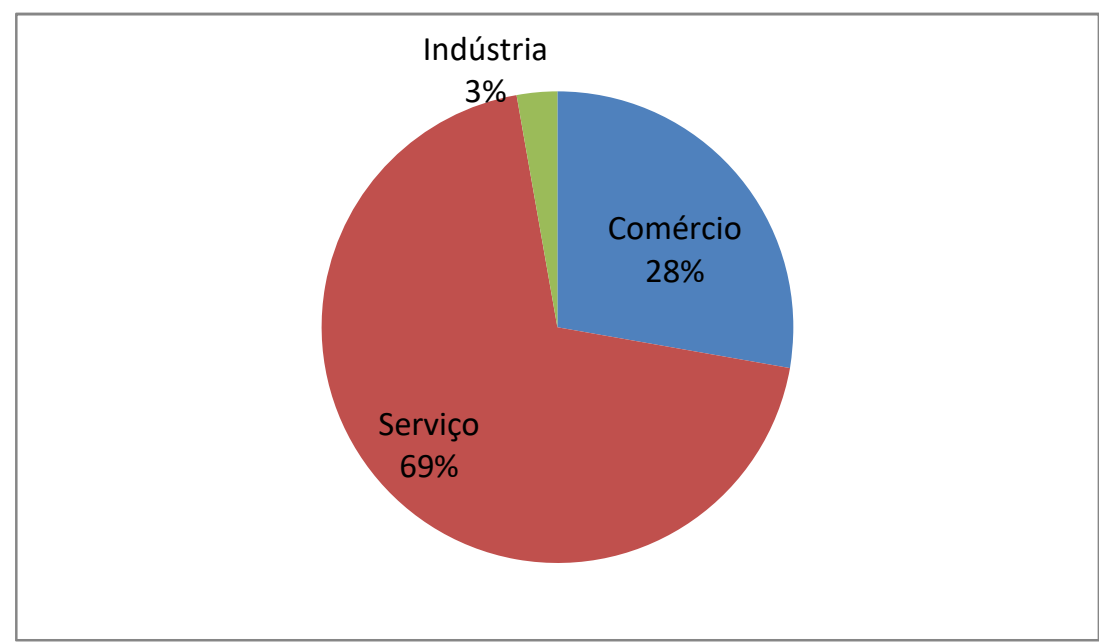

Fonte: Dados da pesquisa.

A tabela 3 apresenta a frequências dos empresários no SEBRAE, com isso, foi possível perceber que a maior quantidade de empresários estava presente pela sua primeira vez:

REMIPE- Revista de Micro e Pequenas Empresas e Empreendedorismo da Fatec Osasco V. 4, N¹, jan.-jun. 2018. 
Tabela 3 - Levantamento por tempo:

\begin{tabular}{|c|c|c|}
\hline Descrição & Quantidade de empresários & Percentual \\
\hline Primeira Vez & 17 & $47,22 \%$ \\
Menos de 6 meses & 1 & $2,78 \%$ \\
Entre 6 meses e 1 ano & 4 & $11,11 \%$ \\
Entre 1 e 2 anos & 5 & $13,89 \%$ \\
Mais de 2 anos & 9 & $25 \%$ \\
Total & 36 & $100 \%$ \\
\hline
\end{tabular}

Fonte: Dados da pesquisa.

A tabela 4 apresenta os motivos que os empresários procuram os serviços do SEBRAE. Foi possível perceber que a maioria dos empresários tem objetivo em atender corretamente as exigências legais. Cerca de 38,9\% procuraram o atendimento para entender e acompanhar questões relacionadas às obrigações tributárias; já outra categoria mais citada pelos empresários, foi a procura para melhorar a gestão da empresa por meio do entendimento sobre os gastos, custos, despesas, entre outros.

Tabela 4 - Levantamento por objetivo à procurar do SEBRAE:

\begin{tabular}{|c|c|c|}
\hline Descrição & Quantidade de empresários & Percentual \\
\hline Aprimorar aspectos de propaganda & 2 & $5,6 \%$ \\
$\begin{array}{c}\text { Melhorar a gestão da empresa através de } \\
\text { entendimento dos gastos, custos, } \\
\text { despesas, etc. }\end{array}$ & 9 & $25,0 \%$ \\
$\begin{array}{c}\text { Entender e Acompanhar as obrigações } \\
\text { tributárias }\end{array}$ & 14 & $38,9 \%$ \\
$\begin{array}{c}\text { Melhorar a gestão da empresas e } \\
\text { entender, acompanhar as obrigações } \\
\text { tributárias }\end{array}$ & 1 & $2,8 \%$ \\
$\begin{array}{c}\text { Aprimorar aspectos de propaganda, } \\
\text { melhorar a gestão e entender, } \\
\text { acompanhar as obrigações tributárias } \\
\text { Não respondeu } \\
\text { Total }\end{array}$ & 8 & $22,2 \%$ \\
\hline
\end{tabular}

Fonte: Dados da pesquisa.

Conforme a tabela 5, pode-se perceber que um grande percentual dos empresários, $69,4 \%$, não possui contador específico para a empresa.

REMIPE- Revista de Micro e Pequenas Empresas e Empreendedorismo da Fatec Osasco 
Tabela 5 - Levantamento da contabilidade nas microempresas:

\begin{tabular}{|c|c|c|}
\hline Descrição & $\begin{array}{c}\text { Quantidade de } \\
\text { empresários }\end{array}$ & Percentual \\
\hline $\begin{array}{c}\text { Possuo contador fixo para minha } \\
\text { empresa }\end{array}$ & 2 & $5,6 \%$ \\
$\begin{array}{c}\text { Contrato serviço de escritório } \\
\text { contábil para os serviços } \\
\text { necessários }\end{array}$ & 9 & $25 \%$ \\
$\begin{array}{c}\text { Não possuo contador específico } \\
\text { para a empresa e uso os serviços } \\
\text { do Sebrae } \\
\text { Total }\end{array}$ & 25 & $69,4 \%$ \\
\hline
\end{tabular}

Fonte: Dados da pesquisa.

A tabela 6 demonstra que 54,5\% dos empresários afirmam que as atribuições do contador são: acompanhar a gestão da empresa, as obrigações fiscais e a apuração dos custos, proporcionando um apoio para tomadas de decisões nos processos decisórios.

Tabela 6 - Levantamento sobre as atribuições do contador:

\begin{tabular}{|c|c|c|}
\hline Descrição & $\begin{array}{c}\text { Quantidade de } \\
\text { empresários }\end{array}$ & Percentual \\
\hline $\begin{array}{c}\text { Realizar apurações para obrigações } \\
\text { fiscais e tributárias }\end{array}$ & 11 & $33,3 \%$ \\
$\begin{array}{c}\text { Analisar a gestão da empresa, } \\
\text { apoiando na tomada de decisão } \\
\begin{array}{c}\text { Acompanhar a gestão da empresa, } \\
\text { obrigações fiscais, apoiar no } \\
\text { processo decisório, apuração dos } \\
\text { custos, etc. }\end{array}\end{array} \quad 18$ & $12,1 \%$ \\
Total & 33 & $100 \%$ \\
\hline
\end{tabular}

Fonte: Dados da pesquisa.

Observa-se na tabela 7 , que os empresários têm o intuito de realizar um levantamento sobre a opinião dos empresários sobre as dificuldades que enfrentam nas suas microempresas.

REMIPE- Revista de Micro e Pequenas Empresas e Empreendedorismo da Fatec Osasco 
Tabela 7 - Levantamento sobre as dificuldades que os empresários enfrentam:

\begin{tabular}{|c|c|c|}
\hline Descrição & $\begin{array}{c}\text { Quantidade de } \\
\text { empresários }\end{array}$ & Percentual \\
\hline $\begin{array}{c}\text { Controle e Organização dos aspectos financeiros } \\
\text { Definição de Estratégia de Venda e Propaganda dos } \\
\text { Produtos/Serviços }\end{array}$ & 5 & $17,2 \%$ \\
Redefinição de Estratégias durante a Crise & 6 & $20,7 \%$ \\
$\begin{array}{c}\text { Controle e Organização dos aspectos financeiros e } \\
\text { definições estratégicas de vendas e propagandas } \\
\text { dos produtos/serviços }\end{array}$ & 5 & $20,7 \%$ \\
$\begin{array}{c}\text { Definição de Estratégia de Venda e Propaganda dos } \\
\text { Produtos/Serviços e redefinição de estratégias } \\
\text { durante a crise }\end{array}$ & 3 & $17,2 \%$ \\
Todas as alternativas & 1 & $10,3 \%$ \\
$\quad$ Outros & 3 & $3,4 \%$ \\
$\quad$ Total & 29 & $10,3 \%$ \\
$\quad$ & $100 \%$ \\
\hline
\end{tabular}

Fonte: Dados da pesquisa.

Com isso, percebe-se que a maior dificuldade que os empresários enfrentam são para definir as estratégias de vendas e propagandas dos produtos/serviços e redefinição de estratégias durante crises.

A tabela 8 apresenta o levantamento das preocupações que os empresários possuem nas suas empresas. Observa-se que 3 empresários não souberam responder pois são iniciantes no mercado. Com isso, percebe-se que 51,6\% dos empresários possuem preocupações relacionadas às obrigações tributárias (tributos e impostos a pagar).

Tabela 8 - Levantamento das preocupações dos empresários:

\begin{tabular}{|c|c|c|}
\hline Descrição & $\begin{array}{c}\text { Quantidade de } \\
\text { empresários }\end{array}$ & Percentual \\
\hline $\begin{array}{c}\text { Obrigações tributárias } \\
\text { (tributos e impostos a } \\
\text { pagar) }\end{array}$ & 17 & $51,6 \%$ \\
$\begin{array}{c}\text { Custos dos } \\
\text { serviços/produtos, caixa } \\
\text { e lucro }\end{array}$ & 11 & $33,3 \%$ \\
$\begin{array}{c}\text { Obrigações tributárias e } \\
\text { Custos dos serviços }\end{array}$ & 4 & $12,1 \%$ \\
Outros & 1 & $3,0 \%$ \\
Total & 3 & $100 \%$ \\
\hline
\end{tabular}

Fonte: Dados da pesquisa.

REMIPE- Revista de Micro e Pequenas Empresas e Empreendedorismo da Fatec Osasco 
O gráfico 3 apresenta levantamento que buscou observar se empresários costumam tomar decisões de acordo com as informações recebidas pela consultoria do SEBRAE. Com isso, percebe-se que 50\% dos empresários sempre absorvem as informações disponibilizadas nas consultorias para tomar decisões.

Gráfico 3 - Levantamento das tomadas de decisões dos empresários com base nas informações recebidas nas consultorias:

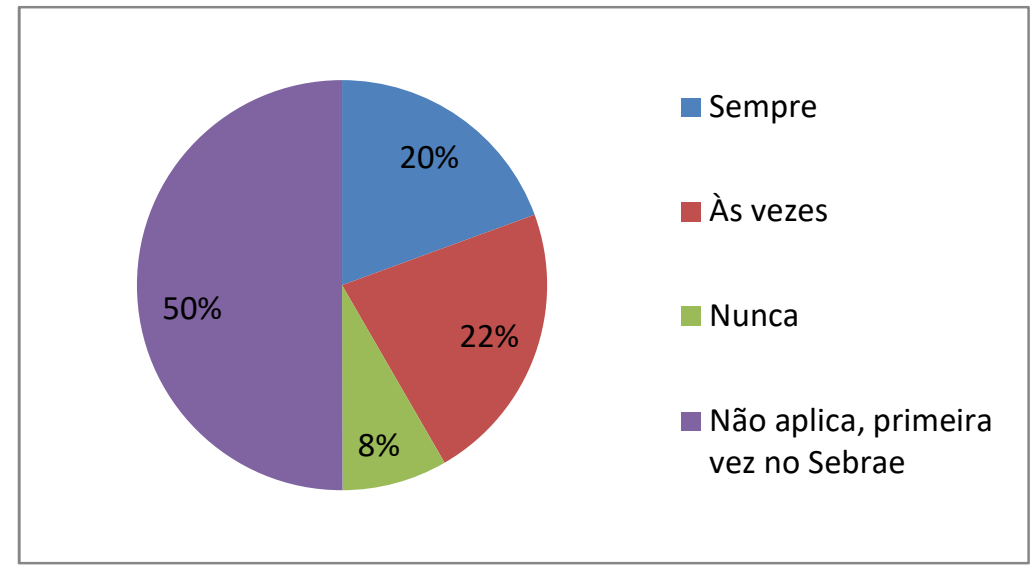

Fonte: Dados da pesquisa.

A tabela 9 apresenta o levantamento da opinião dos empresários referente aos principais benefícios da consultoria do SEBRAE. Com isso, percebe-se que 8,3\% dos empresários não responderam, pois eram iniciantes e 41,7\% dos empresários informaram que as consultorias do SEBRAE auxiliam na gestão da empresa, com informações financeiras sobre custos, despesas, receitas, caixa e lucro.

Tabela 9 - Levantamento dos principais benefícios da consultoria do SEBRAE: 


\begin{tabular}{|c|c|c|}
\hline Descrição & $\begin{array}{c}\text { Quantidade de } \\
\text { empresários }\end{array}$ & Percentual \\
\hline $\begin{array}{c}\text { Não responderam (iniciantes) } \\
\text { Auxilia na gestão da empresa, com informações } \\
\text { financeiras sobre custos, despesas, receitas, } \\
\text { caixa e lucro. }\end{array}$ & 3 & $8,3 \%$ \\
Auxilia na adoção de novas estratégias para \\
empresa
\end{tabular}

Fonte: Dados da pesquisa.

O gráfico 4 apresenta levantamento da avaliação dos empresários referente a qualidade da prestação de serviço do SEBRAE, com isso, sendo que $8 \%$ não responderam, pois são iniciantes. Foi observado que 47\% consideram a consultoria do SEBRAE como excelente.

Gráfico 4 - Levantamento da avaliação da consultoria do SEBRAE:

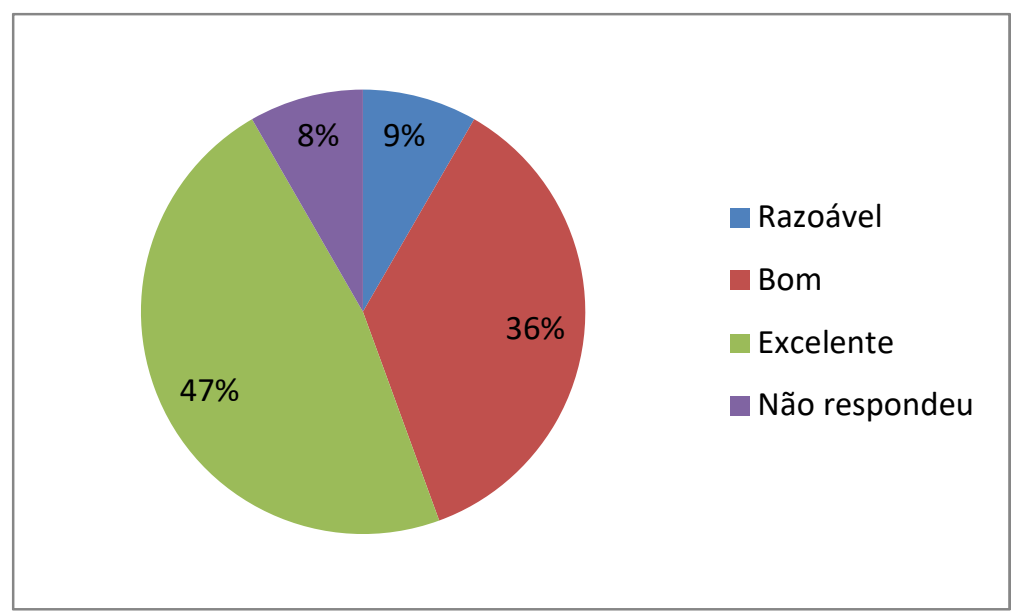

Fonte: Elaborado pelo autor

Para sintetizar a análise, observa-se que as microempresas representam um percentual que totaliza $69 \%$ são do ramo da prestação de serviço.

Sobre o tempo de consultoria, observa-se que 47,2\% informaram que era a primeira vez, sendo que $38,9 \%$ dos empresários informaram que tem como objetivo procurar o SEBRAE para entender e acompanhar as obrigações tributárias.

REMIPE- Revista de Micro e Pequenas Empresas e Empreendedorismo da Fatec Osasco 
Foi observado que $69,4 \%$ não possuem contador específico para a empresa e usa apenas o serviço do SEBRAE, sendo que 54,5\% dos empresários entendem que as atribuições do contador são de acompanhar a gestão da empresa, as obrigações físcais e apoiar no processo decisório e apuração dos custos e entrada de recursos.

Percebeu-se, também, que 20,7\% citam a definição de estratégia de venda e propaganda dos produtos/serviços como dificuldade que os empresários enfrentam e o mesmo número de respondentes considera a redefinição de estratégias durante a crise.

\subsection{AS CONSULTORIAS NO SEBRAE: ENTREVISTAS COM OS CONSULTORES;}

Para os consultores, houve a aplicação de um roteiro de entrevista, de forma qualitativa, com um total de quatro entrevistados. Esse número foi devido à redução de pessoal, pois os consultores haviam sido convocados para feira do empreendedor na cidade de Caruaru, dificultando a aplicação.

Considerou-se relevante possuir conhecimento acerca da experiência dos consultores, haja vista que quanto maior a experiência deles, melhor a expectativa de obter detalhes acerca do processo consultivo. Dos quatro entrevistados, apenas um é consultor voluntário e trabalha na área há 8 anos; outro é prestador de serviço e está no SEBRAE há 4 anos. Os demais são funcionários, sendo um na qualidade de analista há 1 ano e outro consultor credenciado está no SEBRAE há 5 anos.

Não houve diferença nas respostas dos entrevistados, mesmo com diferentes experiências, quando questionados sobre o procedimento para se ter acesso às consultorias fornecidas pelo SEBRAE. Verificou-se que não existe um critério rígido para acesso à consultoria, e qualquer pessoa que precisa de uma consultoria do SEBRAE basta ligar para marcar uma visita técnica com algum consultor na sua empresa ou ir presencialmente ao SEBRAE no horário de funcionamento. $\mathrm{O}$ acompanhamento dessas empresas é realizado por meio de cadastro, tanto para empresas quanto para microempreendedores. Assim, a continuidade do serviço de consultoria pode ocorrer de forma sistemática, caso o empresário necessite.

Embora o foco da consultoria seja voltado principalmente para aquelas empresas que já estão funcionando e estão respectivamente formalizadas, três entrevistados 
afirmaram que a consultoria é acessível às pessoas que também estejam pensando em iniciar um negócio, não se restringindo à pessoa jurídica. Este fato contribui com a diminuição de problemas gerenciais no curso dos negócios. Segundo os consultores, os principais benefícios da consultoria advêm da melhoria da administração da empresa, apesar de outros pontos como auxílio na obtenção de financiamento e estratégias de marketing também serem tratados. O entrevistado 1 afirmou "O principal [benefício] é a parte de organização da empresa, porque realmente a casa está mal arrumada, pois a maior parte das empresas são formadas sem planejamento". O entrevistado 2 reforça afirmando que o principal benefício é "o ensinamento de como administrar a empresa, mostrando soluções tanto financeiras como gerenciais".

Os principais benefícios surgem da resolução dos problemas enfrentados pelos empresários que demandam pelos serviços do SEBRAE. Segundo os consultores, as dificuldades mais comuns dos empresários estão relacionadas à falta de planejamento e de conhecimento do negócio. O entrevistado 1 afirma que o principal problema "é a falta de planejamento, pois se não houver planejamento não haverá controle financeiro e nem controle gerencial”. Alinhando-se a essa mesma concepção, o entrevistado afirma que: “as maiores dificuldades hoje dos empreendedores é a falta de planejamento do seu negócio, um bom planejamento é fundamental para uma empresa". O entrevistado 2 reforça a deficiência da análise do mercado: "a falta de conhecimento do mercado", enquanto o entrevistado 3 enfatiza: "as maiores dificuldades das empresas hoje em dia são na área financeira e mercadológica".

Embora sejam conhecidas as principais dificuldades das empresas e haja a disponibilização dos serviços de consultoria, os entrevistados afirmam que tal projeto não desencadeia sucesso quando o empresário, por diversos motivos, não consegue aplicar na prática o que aparenta ser a solução. A busca pela consultoria do SEBRAE indica uma predisposição à preocupação com os aspectos gerenciais/financeiros. Segundo os entrevistados, embora também estejam disponíveis para solucionar problemas fiscais ou tributários, essa não é a principal demanda dos empresários. O entrevistado 4 reforça a ideia da busca pelo aspecto gerencial de igual forma ao aspecto tributário: "a maioria dos empreendedores procuram os dois aspectos, aqui no SEBRAE existem consultores/especialistas dando suporte para cada área de uma empresa". Verificou-se 
ainda que vários consultores no SEBRAE, conforme as suas áreas, realizam atendimentos ao público no próprio SEBRAE, ou fazem visitas técnicas. Nestas consultas, o analista/consultor pede informações da empresa e faz um diagnóstico do que ela precisa

Apesar de os consultores auxiliarem no processo decisório, verificou-se que a maioria dos empreendedores já vão para o SEBRAE em busca de uma solução para melhorar a situação da empresa, ou tirar dúvidas sobre as gestões financeira e gerenciais. Mas, quando os processos envolvem decisões envolvendo aprimoramento nos registros contábeis, os consultores solicitam que o empresário procure um contador para fazer a contabilidade da empresa.

Como sugestões para melhoria da gestão das empresas que buscam pela consultoria, os consultores afirmam que algumas ferramentas podem ser úteis. $\mathrm{O}$ entrevistado 1, por exemplo, afirma: "Um sistema de software de gestão chamado "ERP", que faz o controle de estoque, custos e vendas, só que os empresários não utilizam por esquecer de informar os dados no sistema ou por ser moderno e não usar". O entrevistado 2 especifica que "a mais básica e simples ferramenta é o fluxo de caixa, que muitos empreendedores sabem fazer". Além dessas, os entrevistados 3 e 4 informaram que as ferramentas que devem ser utilizadas pelos empreendedores são os controles de estoques, fluxos de caixa e gestão financeira.

As consultorias fornecidas pelo SEBRAE auxiliam na utilização e elaboração de tais ferramentas, embora todos entrevistados esclareceram que, além das consultorias, o SEBRAE fornece educação empresarial aos empreendedores através de palestras, oficinas, cursos, treinamentos e capacitações.

\section{CONSIDERAÇÕES FINAIS:}

De acordo com as informações apresentadas, é possível identificar que existe um não completo alinhamento entre a percepção dos consultores e dos empresários. $\mathrm{O}$ primeiro grupo possui maior enfoque no atendimento à parte tributária, no entanto, eles compreendem que o SEBRAE também oferta informações gerenciais, que muitas vezes não são aplicadas. 
O segundo grupo traz a percepção de que o atendimento do SEBRAE fornece informações tributárias e gerenciais. Além disso, é organizado de forma padronizada e pode ser diversificado mediante à necessidade do empresário.

A maioria dos empresários respondeu que busca atendimento com enfoque nas questões tributárias, pois não possui contador, acredita que as atribuições destes profissionais seja acompanhar a gestão da empresa e atender às obrigações fiscais.

Atualmente, as dificuldades que tais empresas estão passando estão direcionadas à definição de estratégia de venda e propaganda, além disso, a crise financeira tem afetado alguns dos estabelecimentos. No entanto, apenas $20 \%$ colocam em prática as orientações ofertadas pelos consultores do SEBRAE. Segundo os empresários entrevistados, os benefícios auxiliam na gestão financeira de custo, despesa, receita, caixa e lucro. De forma geral, avaliaram a consultoria como excelente.

Os consultores realizam um atendimento padrão, sendo que existe um sistema com os dados dos empresários e quem estiver no atendimento os receberá, por isso, não fazem acompanhamento da evolução das empresas. Segundo os consultores, as dificuldades consistem no planejamento financeiro e gerencial, falta de conhecimento do mercado e falta de inovação. Na maioria dos casos, a busca acontece nas áreas tributárias e gerenciais, para tomada de decisão. Normalmente as empresas já possuem problemas e procuram o SEBRAE como fonte de apoio e recebem suporte técnico aplicado de acordo com o perfil da empresa e os benefícios são organização empresarial, soluções financeiras e gerenciais. Contam ainda com cursos, treinamentos e capacitações.

Esta pesquisa limitou-se a uma quantidade pequena de entrevistados. Para estudos futuros, sugere-se ênfase no tema encerramento de micro e pequenas empresas e estudos envolvendo atuação do SEBRAE ou instituições semelhantes.

\section{REFERÊNCIAS:}

Brizolla, M. M. B. (2008). Contabilidade Gerencial. Coleção educação a distância. IjuíRS-Brasil: Unijuí.

Chér, R. (1991). A gerência das pequenas e médias empresas: o que saber para administrá-las, 2ed. rev. e ampl. São Paulo: Maltese. 
Chiavenato, I. (2007). Empreendedorismo dando asas ao espírito empreendedor. São Paulo: Saraiva.

Fernandes, A. M.; Galvão, P. R. (2016). A Controladoria como ferramenta de gestão nas micro e pequenas empresas: um estudo da viabilidade e da relação custo benefício. Revista de Tecnologia Aplicada, v. 5, n. 1, p. 3 - 16.e

Garrison, R.; Brewer, P.; Noreen, E. (2013). Contabilidade Gerencial. 14. ed. [S.1.]: Amgh Editora, 2013.

Iudícibus, S. D. (1998). Contabilidade Gerencial. 6a. ed.; São Paulo: Atlas - Grupo Gen, 1998. (Livro-Texto).

Longenecker, J. G.; Moore, C. W.; Petty, J. W. (1998). Administração de pequenas empresas. São Paulo: Makron Books.

Marion, J. C. (2011). Contabilidade empresarial. 10o. ed. [S.1.]: Atlas.

Menezes, C. R. C. De; Olave, M. E. L. (2016). Práticas de gestão do conhecimento em micro e pequenas empresas de Sergipe. Gestão \& Regionalidade, Sergipe, v. 32, n. 94.

Monteiro, J.; Barbosa, J. (2011). Controladoria Empresarial: Gestão Econômica para as micro e pequenas empresas. Revista de Micro e Pequena Empresa. Campo limpo Paulista, v. 5, n.2, P.38 - 59, Maio/Agosto.

Raza, C. (2008). Informações contábeis: o cliente não sabe pedir e o escritório contábil, na sua grande maioria, não está preparado para fornecer. Boletim CRC SP, São Paulo, n.166, p.16-17. 